\title{
Is current knowledge about psychopathy reflected in Fon Ronson's book The Psychopath Test: A Journey Through the Madness Industry? - controversies around psychopathy
}

\author{
Beata Pastwa-Wojciechowska ${ }^{1}$, Márta Fülöp $p^{2}$ \\ 1: Institute of Psychology, University of Gdansk, Gdansk, Poland \\ 2: Institute of Cognitive Neuroscience and Psychology, Hungarian Academy of Sciences, Hungary
}

In the article we try to respond to a question about the ways current knowledge about psychopathy is reflected in Jon Ronson's book The Psychopath Test: A Journey Through the Madness Industry. Such a response seems necessary since the subject matter of psychopathy is still interesting due to its complexity, and is associated with the quest for the sources of evil in human beings. The term psychopathy also refers to personality disorders. Therefore, controversies might arise when it comes to the use of clinical knowl- edge and various verification methods by non-experts in this field. It seems that such situations bring our attention to those issues that need improvement in science. It is our hope that this article might add some reflections to the discussion about the necessity of "protecting" clinical knowledge from its extensive popularization.

KEY WORDS

psychopathy; diagnosis; controversies

CORResponding Author - Prof. Beata Pastwa-Wojciechowska, Institute of Psychology, University of Gdansk,

4 Bażyńskiego Str., 80-952 Gdansk, Poland, e-mail: psybpw@ug.edu.pl

AUthors' CONTRiBution - A: Study design - B: Data collection - C: Statistical analysis - D: Data interpretation .

E: Manuscript preparation · F: Literature search · G: Funds collection

TO CITE THIS ARTICLE - Pastwa-Wojciechowska, B., \& Fülöp, M. (2016). Is current knowledge about psychopathy

reflected in Jon Ronson's book The Psychopath Test: A Journey Through the Madness Industry? - controversies around psychopathy. Current Issues in Personality Psychology, 4(1), 11-17.

RECEIVED 15.12.2015 · REVIEWED 29.02.2016 · ACCEPTED 07.03.2016 · PUBLISHED 16.03.2016 
Is current knowledge about psychopathy reflected in Jon Ronson's book The Psychopath Test:

A Journey Through the Madness Industry?

Is the current knowledge on psychopathy reflected in Jon Ronson's book The Psychopath Test: A fourney Through the Madness Industry? Why did it generate controversies, and what kind? In 2014 the translation of Jon Ronson's book The Psychopath Test: A fourney Through the Madness Industry was published in Poland by Insignis. The book was very well received by readers, as the world of psychopathy and psychopaths still sparks interest due, on one hand, to its intriguing complexity and, on the other hand, to the ever pervasive question about the causes of evil in humans. However, it is worth noting that the book started a discussion among scientists as well and became the subject of professionals' appeal especially because the book popularizes and trivializes expert (clinical) knowledge with the uncritical conviction that one can master skills needed to diagnose other people without special education. Therefore, in Current Issues in Personality Psychology, a journal that publishes studies concerning broadly defined personality, we decided to draw attention to the above-mentioned issues. We think that the author indicates that there is a need for expert knowledge to diagnose psychopathy. On one hand he clearly indicates that he is not an expert, while on the other hand he behaves as if he is, often ironically, and therefore does not make his message clear sometimes. Such an attitude may confuse readers, especially those who are not mature and competent enough in this area of knowledge. The problem of psychopathy evokes interest among experts and laypersons alike. The number of publications dedicated to psychopathy constantly increases, e.g. about the psychopathic personality, its theory of development, etiology, structure clinical diagnosis, as well as the diagnostic methods. In spite of this, the discussion among theoreticians and practitioners about the essence of this term remains unsettled, and the complexity and numerous aspects of the problems indicated in the literature increase the awareness of responsibility when using this term. The main responsibility is a reliable, objective and fairly detailed description of different theories, concepts, opinions and views expressed by people whose work concerns psychopathy. Psychopaths fascinate not only because of their personality but also the effectiveness of their actions, and that is despite the fact that they may achieve their goals unlawfully, without respecting other people's subjectivity and their rights. On one hand we want to get to know them and learn to differentiate these predators from other people, but on the other we may be fascinated and impressed with their actions and their sometimes dubious successes. Just have a look at the number of websites dedicated to serial killers, who are very often identified with psychopathic personality, and at the fascination with murder, demonstrated by the number of people who visit these websites.
Leaving out but not underestimating the historical contribution of psychopathy research, two experts who had a decisive role in the reactivation and development of psychopathy research need to be mentioned. They are Hervey Cleckley (1941) and Robert D. Hare (1970, 1980, 1985, 1991, 1996). Cleckley's book The Mask of Sanity (1941/1976) formulated three theses about psychopathy: 1) it is necessary to go back to the definition of psychopathy, 2) it is necessary to compile strict diagnostic criteria and 3) there are psychopaths not only among people who violate law but also among ordinary citizens who are among us, in our daily life. Interestingly, the first two ideas were reflected in numerous studies, but the third thesis waited to be taken into consideration almost until the publication of the book by Paul Babiak and Robert D. Hare (2007) Snakes in Suits. When Psychopaths Go to Work. Robert D. Hare (1970, 2003a) authored the operational definition of psychopathy, which is tested predominantly with the Psychopathy Checklist-Revised (PCL-R) created by him. However, the path to create the tool that is currently considered one of the best diagnostic methods was not straightforward. Striving towards more precise definition and unification of diagnostic criteria of psychopathy, Hare (1985) created an operational definition. It was based on clinical and empirical research and enabled assessment of the important traits of this personality type and differentiation of psychopathy from antisocial and unlawful behaviors. To identify the pivotal psychopathy traits, Hare and his colleagues (1991) used the following methods: a list of psychopathy traits created based on Cleckley's theory, psychiatric criteria of antisocial personality disorder included in the successive editions of Diagnostic and Statistical Manual (DSM-III, DSM-III-R and DSM-IV; American Psychiatric Association, 1980, 1987, 1994), test methods such as the Minnesota Multiphasic Personality Inventory (MMPI), and the Socialization Scale from Gough's California Personality Inventory. He also included those personality and temperamental traits that, based on theoretical and empirical findings, should be associated with psychopathy, i.e., sensation seeking, impulsiveness, lack of empathy, extraversion, psychoticism, neuroticism and anxiety. This conceptualization of psychopathy resulted from the following premises:

- Hare disagreed with the stand of creators of diagnostic criteria of antisocial personality disorder who focused on identifying the easily observed antisocial behaviors while neglecting personality traits.

- He strived towards creating a reliable and valid concept of psychopathy.

- He wanted to create an operational construct that would - in line with the clinical tradition - include both personality traits and specific behavioral patterns.

- He postulated that individuals who fulfill psychopathy criteria are similar on many levels: be- 
haviors and lifestyle as well as affective traits and type of interpersonal relations.

- He also emphasized that no single isolated symptom is sufficient to diagnose psychopathy.

According to Hare, a psychopath's behavior might be analyzed in two dimensions. A psychopath is an impulsive, irresponsible, hedonistic person who lacks the ability to experience normal emotional elements of interpersonal behavior, i.e., guilt, remorse, empathy and authentic emotional focus on other people's well-being. Although such a person is often capable of normal mimic expression of emotions and of simulating feelings, the social and sexual relationships with others remain superficial and exploitative. Psychopaths' judgments are superficial and they themselves seem to be unable to delay fulfilling their current needs regardless of the consequences for themselves and others. The operational definition of psychopathy enables measurement of two factors, each one assessed with 10 items. Factor 1 describes the constellation of psychopathic traits that many clinicians consider fundamental in this personality type, and these are characteristics related to interpersonal and emotional attitudes of psychopaths towards the environment and the verbal style of functioning. Factor 2 describes the behaviors that indicate impulsiveness, lack of stability and antisocial lifestyle (Hare, 1985, 1991, 2003a,b; Harpur, Hare, \& Hakstian, 1989, 1991). In other words, the PCL-R contains the following 20 items: 1) glibness, superficial charm, 2) grandiose sense of self-worth, 3) proneness to boredom, 4) pathological lying, 5) conning, manipulativeness, 6) lack of remorse, 7) shallow affection, 8) callous, lack of empathy, 9) parasitic lifestyle, 10) poor behavioral controls, 11) promiscuous sexual behavior, 12) early behavioral problems, 13) lack of realistic, long-term goals, 14) impulsiveness, 15) irresponsibility, 16) failure to accept responsibility, 17) many short-term marital relationships, 18) juvenile delinquency, 19) revocation of conditional release, 20) criminal versatility. It is thus evident that the concept of psychopathy by Robert D. Hare lists very precisely the variables that constitute this personality type and specifies the rules of assessment.

As a result of the studies 22 criteria were initially created based on which psychopathy was diagnosed (the Psychopathy Checklist - PCL) and, after publication of DSM-III-R, the Psychopathy Checklist-Revised (PCL-R) (Pastwa-Wojciechowska, 2004). The PCL-R was prepared based on the analysis of diagnostic utility of each PCL item and other researchers' suggestions (Hare, 2007). The number of 20 items was reduced by the elimination of points: "drug or alcohol overuse is not a direct cause of antisocial behavior" and "earlier diagnosis of psychopathy or a similar diagnosis", due to difficulties in assessment and low utility of the obtained information.
As a first step of the process of creating these criteria, Hare compiled a comprehensive clinical procedure during which prisoners were evaluated on a 7-point scale that aimed to assess to what extent their displayed and stable behaviors and personality traits were in line with Cleckley's clinical construct of psychopathy. However, practical implementation of this method was very limited - it required from the evaluator not only deep clinical understanding of applied criteria but also the ability to integrate information from various sources (interview, data from other sources such as case files). Despite high reliability of the evaluations made by people assessing the frequency of particular reactions described in the above-mentioned points among observed persons, it turned out that for those who did not have a theoretical and practical background, it was hard to identify which indicators exactly were used in the procedure (Hare \& Neumann, 2006). Consequently, a need to create a simple and more objective procedure emerged. Thus, the following evaluation criteria were devised: 0 - trait was absent or not applied, 1 uncertainty whether the trait is applied, 2 - trait was present. In other words, each of the twenty items in the PCL-R is evaluated on a three-point scale $(0,1,2)$, based on the degree to which a given trait or behavior fits the evaluated person. The researcher assesses the participant with regard to each of the traits included in the test. Number 0 means that the given trait does not describe the person. Number 1 means a medium intensity of the trait (i.e., the trait is present so 0 cannot be ascribed but it is not intensive enough to assign 2 points), and it is also assigned when there are discrepancies between data gathered during the interview with the person and the data found in the records. Number 2 means the maximum intensity of the trait (it reflects the core behavior or characteristic personality trait). The person can obtain a maximum of 40 and a minimum of 0 points. Additionally, for every position it is stated when we use 0,1 or 2 points. For example, for position 20 (criminal versatility) it is defined that 2 points are assigned to a person who has committed 6 or more kinds of acts, 1 to a person who has committed 4-5 distinct acts, and 0 to a person who has committed 3 or fewer distinct acts. It is thus an assessment method that uses rating scales. A psychopathic disorder is identified when a person scores 30 or more points (Hare, 1991, 2003a,b). It needs to be noted that people who meet the criteria of psychopathy are alike on many levels: behavior, lifestyle, affective traits and type of interpersonal relationships. Unlike the diagnostic criteria for antisocial personality disorder (APD), no single isolated set of symptoms suffices to identify psychopathy (Harvé, 2007). Therefore, diagnosis is based on clinical knowledge, and is also based on the assessment criteria included in the test and requires them to be correlated with other sources 
Is current knowledge about psychopathy reflected in Jon Ronson's book The Psychopath Test:

A Journey Through the Madness Industry?

of information. Information used in the procedure is obtained during observation (assessment of interaction, lifestyle cohesion, personality traits, behaviors), interview (about education, employment, family, interpersonal relations, behaviors during adolescence and antisocial behaviors) and documentation analysis (case files, medical records, etc.). It is advised to use all these sources; cases when only the additional data obligatory for valid assessment were used (i.e., case files analysis) demonstrated limited ability to assess features such as glibness, superficial charm and many other personality traits.

On the website of the Society for the Scientific Study of Psychopathy (http://www.psychopathysociety.org) one can read that the psychopathic personality is often misunderstood and that there are a number of disagreements around the diagnostic criteria. Psychopathic personality (psychopathy) is not the same as violence, serial killing, psychosis, mental illness (psychopathology) in general or antisocial personality disorder. In other words, "psychopathy IS: A constellation of traits that comprises affective features, interpersonal features, as well as impulsive and antisocial behaviors. The affective features include lack of guilt, empathy, and deep emotional attachments to others; the interpersonal features include narcissism and superficial charm; and the impulsive and antisocial behaviors include dishonesty, manipulativeness, and reckless risk-taking. Although psychopathy is a risk factor for physical aggression, it is by no means synonymous with it. In contrast to individuals with psychotic disorders, most psychopaths are in touch with reality and seemingly rational. Psychopathic individuals are found at elevated rates in prisons and jails, but can be found in community settings as well" (http://www.psychopathysociety.org/ en/home.html).

Moving on to the description of the book by Jon Ronson, it has to be noted that its aim was to show the readers the challenging path that the author took when overcoming his weaknesses. In our understanding, the author's aim was to solve a mystery, and the book is like a detective story. It is worth noting that Jon Ronson is not a psychologist or a psychiatrist, but a journalist who was asked by a researcher who specialized in neurology to solve a certain mystery. The researcher and other people received an encoded book from an anonymous sender. The book only had 42 pages, and every other page was empty. The author of this unusual publication was Joe K, and its title was Being or Nothingness. This is where Jon and his readers' trip began, into the dark and not easily accessible regions of the psychopathic personality. The book consists of 11 chapters and each one of them is a specific step in getting to know psychopaths, leading Jon Ronson to achieve his objective of solving the puzzle of the mysterious book. The meeting of Ron with Essi Viding, an expert (Uni- versity College London) who "dealt with psychopaths", made him realize that he had never bothered with psychopaths. However, he asked himself if he shouldn't pay more attention to them. He thought it was extraordinary that "somewhere there live people who, because of neurological disorders, are as scary, as the most sinister representatives of alien civilizations from SF" (p. 21). He started recalling psychologists saying that there were many psychopaths in the world of business or politics, and among successful people, and that the lack of empathy benefits those who move in those circles. Jon Ronson reached for DSM-IV-TR (American Psychiatric Association, 2000), which he bought in order to look for disorders that make the affected persons try to gain power over others. We can ask here if such easy access to literature related to professional diagnosis is not a specific kind of danger. The answer seems to be obvious, because drawing conclusions about others based only on the diagnostic criteria can sometimes and often does lead to oversimplifications or even gives certainty to nonprofessionals that they possess the knowledge about others and that they can - just like the professionals - diagnose people. In Chapter 4, titled "How to identify a psychopath", the readers can familiarize themselves with the Psychopath Checklist-Revised (PCL-R) (Hare, 1991, 2003a,b). Ronson describes each test item in a simple manner, and also in regard to case studies ("The case of H.," "The case of J."), that were discussed during a workshop by Robert Hare. In other words, Ronson visits criminals and people considered to be psychopaths, comparing the knowledge about them with the knowledge of psychologists and psychiatrists, such as Robert D. Hare, Essi Viding or David Cook. He meets with such people as Toto (a former chief of the Sicilian Mafia) and Albert J. Dunlap (a famous businessmen accused of fraud) who are suspected to be psychopaths, and Tony, a young criminal, who believes he is a victim of a psychiatric diagnosis. It should certainly be noted that Jon Ronson tried to learn about different aspects related to the diagnosis of psychopathy and to the therapeutic and resocialization methods of work. In the book one can read a description of the Broadmoor Hospital in the UK, formerly known as the Broadmoor Institute for the Criminally Insane and its ward for patients with 'dangerous severe personality disorder', and learn about an experiment conducted by the Canadian psychiatrist Eliot Barker at Oak Ridge in the 1970s. The specific sense of humor and the charm of Jon, and his innate curiosity, make the book The Psychopath Test: A fourney Through the Madness Industry a captivating read. This seemingly light reading reveals some uncomfortable truths and encourages readers to ask questions about how to define normality in the world in which we are more and more often evaluated based on our most extreme behaviors. There remains the question asked 
in the book's title - are you a psychopath? [Are you a psychopath? is the title of the book in Polish]. It seems that the book leaves the reader with this question left open. Ronson shows that it is difficult to decide when a behavior is part of a completely normal person's unique individuality and when it is the indication of a pathology. If this is done without care and sensitive and complex knowledge, anybody can be diagnosed with a number of disorders. Some highly influential experiments in the 1970s proved that once somebody is diagnosed with a mental illness it is extremely difficult to prove the opposite, and any persistent and strong attempt to negate the diagnosis may mean to other people that in fact the diagnosis is accurate. The intention of the author was probably not to speak out against expert knowledge but rather to confront the issue as a layman who seeks to solve a riddle. The book itself became the subject of discussion on various levels - clinical, methodological and social - and this is why it can arouse controversy, or be a source of questions for consideration (PastwaWojciechowska, 2013).

The first question that comes to mind, and is inseparable from the discussed problem, is whether, based on it, the knowledge concerning the diagnosis of psychopathy is over trivialized. When describing the diagnostic criteria for psychopathy and the way they are administered to the people he meets, Ronson does it in a way which suggests that it is sufficient to just know the criteria, and he completely ignores the context associated with the administration of the test and the necessary education and clinical knowledge. It is worth noting that this tool belongs to a group of clinical tests, and when purchasing it, it is necessary to fulfill the criteria set by the editor, which includes recommendations from two clinicians. The readers, after familiarizing themselves with Ronson's book, may have the wrong impression that the diagnosis of psychopathy is very simple and can be learned by reading a book. Certainly the knowledge that the experts shared with Ronson was presented to him in the context of the case he was working on, and it was fragmented and only constituted an answer to questions asked. Judging by the author's writing style, he gives an impression of a pleasant interlocutor, maybe a little lost, whom we want to help and who really wanted to take on a case which stimulated his cognitive curiosity on different levels. Thus, in my opinion we can hardly suspect him of bad intentions. At the same time, a reader who is not a professional may feel an overwhelming desire to diagnose other people and to draw farfetched conclusions.

The second question that arises is whether the knowledge about psychopathy as provided by the author is sufficient to answer the title question - Are you a psychopath? The critique that followed the book concentrates on the lack of real insight into the issue of psychopathy. From the professionals' point of view, the presented information is superficial and fragmented, giving the impression that the author wanted to confirm his assumptions. A confirmation of this kind of answer is the statement made in the commentary by Robert D. Hare on the book and by other internationally recognized researchers of psychopathy, which was posted on the website of the Society for the Scientific Study of Psychopathy (http:// www.psychopathysociety.org). We quote their statement below:

General Ronson Commentary:

Jon Ronson's new book The Psychopathy Test has gained substantial attention in the media. The book is no doubt an entertaining read; Ronson is well practiced in his craft. However, those contacted by Ronson during his collection of material for the book, were taken aback to find that the book contained 'liberal' and/ or fictional accounts of their interactions with him. Perhaps artistic license is an inevitable part of Ronson's chosen profession, although it is disappointing when it is used dishonestly and in a manner that undermines other people's professional credibility.

As psychopathy researchers our primary concern rests with the book's treatment of psychopathy and its measurement. The 'psychopathy test' in Jon Ronson's new book is the Hare Psychopathy Checklist-Revised (PCL-R). The PCL-R is a clinical instrument designed for use by qualified clinicians authorized by law and professional organizations to administer and interpret psychological tests, or by researchers who report only group scores. Many clinicians and researchers, as well as judges, prosecutors, defense attorneys, and investigators attend PCL-R Workshops, in some cases merely to learn something about psychopathy. This does not qualify them to use the PCL-R unless they meet the appropriate legal and professional standards. We are concerned that Ronson describes the workshop he attended as providing him with a powerful tool to pick out psychopaths. It does nothing of the sort.

We were particularly surprised at an apparent contradiction: Ronson queried the use of the PCL-R as a diagnostic instrument in the prison/special hospital setting, yet embarked on a journey in which he diagnosed various members of the general public, using his 'power to identify a psychopath merely by spotting certain turns of phrase'. PCL-R assessments require the integration of information from interview, file, and collateral sources. Information from these various sources is rarely available unless someone is already in the mental health or criminal justice systems. Further, the scoring of items requires close adherence to 
Is current knowledge about psychopathy reflected in Jon Ronson's book The Psychopath Test:

A Journey Through the Madness Industry?

the formal item descriptions contained in the manual. Ronson is not legally or professionally entitled to have or use these scoring criteria, and his tactic of pulling up one- or twoitem titles to label someone is sharply at odds with the appropriate use of the instrument. It also is stigmatizing for those so identified. The threshold score for psychopathy is very high and certainly cannot be reached by a layman's assertions that someone scores high on a few items. We fear that Ronson's book does a disservice to the clinicians and researchers who use it properly, and serves to undermine their efforts to ensure that the PCL-R should be used properly or not at all.

In short, we think that Ronson's book trivializes a serious personality disorder and its measurement, which is not helpful to those who have the disorder or to their unfortunate victims.

This statement was signed by such experts as: Robert Hare (University of British Columbia), Essi Viding (University College London), Adrian Raine (University of Pennsylvania), Joe Newman (University of Wisconsin), Madison Kent (Kiehl, University of New Mexico), Dave Kosson (Rosalind Franklin University), Randall Salekin (University of Alabama), Craig Neumann (University of North Texas), Edelyn Verona (University of Illinois), Adelle Forth (Caleton University), Raymond Knight (Brandeis University), Paul Frick (University of New Orleans), and Luna Muñoz Centifanti (Durham University). The presented approach confirms the previously underlined arguments and certainly makes it clear that clinical knowledge should be "protected" from its overpopularization. It should also be noted that such a "simplification" of the rules of assessing the psychopathic personality can lead to a further abuse of this concept in everyday language, depriving it of the dimension associated with scientific or medical terms.

It is hard not to notice the positive aspects of this book, such as the interesting writing style of its author, the ease and the style that immerses the reader in the complicated minds of the people he met, or presenting scientific issues in a simple and understandable manner. I think that the readers had a chance to face facts and phenomena about which they wouldn't be able to read in other books, supported by descriptions of specific cases from social life (for example, Al Dunlap's case). They also could find out why some of the authorities in psychology, psychiatry, resocialization or criminology disappeared from the list of recognized authorities and what caused that. He also pointed out to the still reappearing issue of validity and reliability of psychological and psychiatric diagnoses. And, as it seems, he awkwardly fell into a trap (or traps) that he himself wrote about.

Thus, when reading Jon Ronson's book, one should be aware of its limitations related to reliable scientific and clinical knowledge, and the book itself makes us aware how this knowledge can be used and become a tool in the hands of different people. It certainly teaches one to maintain a distance from the statements of nonspecialists on topics concerning very specialized knowledge, but it also demonstrates the need to signal various phenomena in scientific and social life. Just like the Society for the Scientific Study of Psychopathy reacted to some disturbing occurrences, so Jon Ronson drew attention to the flaws of science - among others to the abuse of diagnosis or conducting therapeutic experiments without a scientific base and causing more harm than good. The controversies around the book and the content of the book itself call attention to the need to apply critical thinking and not simplistic approaches, for both professionals and laypersons.

\section{REFERENCES}

American Psychiatric Association. (1980). Diagnostic and Statistical Manual of Mental Disorders ( ${ }^{\text {rd }}$ ed.). DSM-III. Washington: American Psychiatric Association.

American Psychiatric Association. (1987). Diagnostic and Statistical Manual of Mental Disorders ( $3^{\text {rd }}$ ed. rev.). DSM-III-R. Washington: American Psychiatric Association.

American Psychiatric Association. (1994). Diagnostic and Statistical Manual of Mental Disorders ( $4^{\text {th }}$ ed.). DSM-IV. Washington: American Psychiatric Association.

American Psychiatric Association. (2000). Diagnostic and Statistical Manual of Mental Disorders ( $4^{\text {th }}$ ed. text rev.). DSM-IV-TR. Washington: American Psychiatric Association.

Babiak, P., \& Hare, R. D. (2009). Snakes in suits. When psychopaths go to work. Poznań: Jeżeli P to QWydawnictwo.

Cleckley, H. (1941/1976). The mask of sanity. St. Louis: Mosby.

Hare, R. D. (1970). Psychopathy: Theory and Research. New York, Willey.

Hare, R. D. (1980). A research scale for the assessment of psychopathy in criminal populations. Journal of Personality and Individual Differences, 1, 111-117.

Hare, R. D. (1985). Comparison of procedures for the assessment of psychopathy. Journal of Consulting and Clinical Psychology, 53, 7-16.

Hare, R. D. (1991). The Hare Psychopathy Checklist-Revised. Manual. Toronto: Multi-Health Systems.

Hare, R. D. (1996). Psychopathy: A clinical construct whose time has come. Criminal Justice and Behavior, 23, 25-54.

Hare, R. D. (2003a). Hare PCL-R ( $2^{\text {nd }}$ ed.). Toronto: Multi-Health System. 
Hare, R. D. (2003b). Hare PCL-R. Rating Booklet. ( $2^{\text {nd }}$ ed.). Toronto: Multi-Health System.

Hare, R. D. (2007). Forty years aren't enough: Recollections, prognostications, and random musing. In: H. Herve \& J. C. Yuille (eds.), The Psychopath: Theory, Research, and Practice (pp. 3-28). Mahwah: Lawrence Erlbaum Associates.

Hare, R. D., \& Neumann, C. S. (2006). The PCL-R assessment of psychopathy. Development, structural properties, and new directions. In: C. J. Patrick (ed.), Handbook of Psychopathy (pp. 58-88). New York: The Guilford Press.

Harpur, T. J., Hare, R. D., \& Hakstian, A. R. (1989). Two-factor conceptualization of psychopathy: construct validity and assessment. Journal of Consulting and Clinical Psychology, 1, 6-17.

Harpur, T. J., Hare, R. D., \& Hakstian, A. R. (1991). Two-factor conceptualization of psychopathy: construct validity and assessment implications. Psychological Assessment. Journal of Consulting and Clinical Psychology, 1, 6-17.

Harvé, H. (2007). Psychopathy across the ages: A history of the Hare psychopath. In: H. Hervè, \& J. C. Yuille (eds.), The Psychopath: Theory, Research, and Practice (pp. 31-55). Mahwah: Lawrence Erlbaum Associates.

Pastwa-Wojciechowska, B. (2004). Naruszanie norm prawnych w psychopatii. Analiza kryminologiczno-psychologiczna [Violiations of legal norms in psychopathy. An analysis from the point of view of criminal psychology]. Gdańsk, Wydawnictwo UG.

Pastwa-Wojciechowska, B. (2013). Psychopaci sprawcy przestępstw seksualnych [Psychopats - sexual offenders]. Gdańsk, Wydawnictwo Harmonia Universalis.

Ronson, J. (2014). Czy jesteś psychopatą. Fascynująca podróż po świecie obłędu [The Psychopath Test: A Journey Through the Madness Industry”]. Kraków: Wydawnictwo Insignis.

The Society for the Scientific Study of Psychopathy: http://www.psychopathysociety.org/en/home. html 